\title{
Genetic Diversity Assessment and Marker-Assisted Selection in Crops
}

\author{
Francesco Mercati ${ }^{1, *(1)}$ and Francesco Sunseri ${ }^{2, *}$ \\ 1 CNR_Consiglio Nazionale delle Ricerche, Istituto di Bioscienze e Biorisorse (IBBR), Corso Calatafimi 414, \\ 90129 Palermo, Italy \\ 2 Dipartimento di Agraria, Università Mediterranea degli Studi di Reggio Calabria, Loc. Feo di Vito, \\ 89124 Reggio Calabria, Italy \\ * Correspondence: francesco.mercati@ibbr.cnr.it (F.M.); francesco.sunseri@unirc.it (F.S.)
}

Received: 16 November 2020; Accepted: 7 December 2020; Published: 9 December 2020

Global warming is negatively impacting on crop yield and Earth's climate changes can bring possible negative effects on the growth and reproductive success of crops. Therefore, the exploitation of biodiversity is essential to select more resilient genotypes employable in more sustainable cropping systems.

The assessment of genetic diversity from the major crops and their wild relatives together with its exploitation have been always among the main challenges for plant breeding, as recently highlighted [1,2]. The wide utilization of molecular markers for mapping traits of agronomic interest in specific genomic regions appears to return back another pivotal effort for the future development of novel cultivars [3]. Indeed, the improvement of plant breeding efficacy has always gone through the construction of exotic genetic libraries, exploiting the genetic resources [4].

Nowadays, there is evidence that MAGIC and other exotic populations will play a major role in the coming years in allowing for impressive gains in plant breeding for developing new generations of improved cultivars [5].

This Special Issue focused on the application of such advanced technologies devoted to crop improvement, exploiting the available biodiversity in crops. In detail, next-generation sequencing (NGS) technologies supported the development of high-density genotyping arrays for different plants included in this issue.

By using a high throughput approach, here we report a new high-resolution eggplant (Solanum melongena L.) genetic map based on a RIL population and Genotyping by Sequencing (GBS) analysis by which 7249 SNPs were assigned to the 12 chromosomes spanning $2169.23 \mathrm{cM} \mathrm{[6].}$ Afterwards, the phenotyping of the RIL population at three locations allowed us to elucidate the genetic bases of seven traits related to anthocyanin content in eggplant as well as seed vigor. Overall, between 7 and 17 QTLs (at least one major QTL) were identified for each trait [6]. Otherwise, a genome-wide association scan (GWAS) using 121 accessions and a 9K single nucleotide polymorphisms (SNPs) chip were also reported to clarify the genetic determinants underlying drought tolerance in barley (Hordeum vulgare L.) [7]. Overall, a total number of 101 significant SNPs, distributed over all seven barley chromosomes, were found to be highly associated with the studied traits, of which five genomic regions were associated with candidate genes at chromosomes 2 and 3 [7].

The limited availability of simple sequence repeats (SSR) in Paeonia lactiflora, a flowering crop with great economic value, triggered a study to develop a novel SSR panel with Illumina RNA sequencing for also assessing the role of these variants in gene regulation. The results showed that dinucleotides with AG/CT repeats were the most abundant type of repeat motif in P. lactiflora and were preferentially distributed in untranslated regions. Significant differences in SSR size were observed among motif types and locations [8]. This new set of SSRs will aid programs for accession identification, marker-trait association and molecular assisted breeding in P. lactiflora [8]. 
QTL-related Lethal Necrosis (LN) tolerance/resistance in maize (Zea mays L.) has been studied by using five hundred selected kompetitive allele specific PCR (KASP) SNPs and multiple mapping populations [9]. To understand the status of previously identified quantitative trait loci (QTL) in diverse genetic backgrounds, $\mathrm{F}_{3}$ progenies derived from seven bi-parental populations were genotyped and phenotyped under artificial LN inoculation for three seasons. Joint linkage association mapping revealed at least seven major QTL spread across the 7-biparetal populations, for resistance to LN infections potentially useful for marker-assisted breeding [9].

A particular resequencing approach was utilized for exploring the natural variation and the domestication selection of ZmPGP1, involved in the polar auxin transport and associated to plant height, leaf angle, yield traits, and root development in maize (Z. mays L.) [10]. Li et al. (2019) [10] re-sequenced this gene in 349 inbred lines, 68 landraces, and 32 teosintes. Sequence polymorphisms, nucleotide diversity, and neutral tests revealed that ZmPGP1 might be selected during domestication and improvement processes. Marker-trait association analysis identified 11 variants significantly associated with 4 plant architecture and 5 ear traits, revealing that significant variants in ZmPGP1 can be used to develop functional markers to improve plant architecture and ear traits in maize [10].

Another particular approach was reported for two popular fruit crops such as strawberry (Fragaria $\times$ ananassa Duchesne) and raspberry (Rubus idaeus L.). Here, Lebedev et al. (2020) [11] reported the potential transferability between the species of a large SSR panel for their employment in breeding programs assisted by functional DNA markers [11]. One hundred eighteen (118) microsatellite loci in the flavonoid biosynthesis were developed to assess the genetic diversity of 48 Fragaria and Rubus accessions, including wild species and rare cultivars, which differ in berry color, ploidy, and origin. SSR panel may be a useful molecular tool in strawberry and raspberry breeding programs for improvement anthocyanin related traits [11].

Informative molecular markers such as SSR were adopted also for detecting hybridity and homozygosity in breeding segregant populations in lettuce (Lactuca sativa L.). In this study, a panel of 16 SSR was used to genotype 71 putative parental lines and to plan 89 controlled crosses designed to maximize the genetic recombination [12]. Unexpected genotypes were detected (5\%), consistent with this species' spontaneous out-pollination rate. Overall, the synergistic advantages of conventional and molecular selection applied in different steps of a breeding programs aimed at developing new varieties were demonstrated [12].

Two other manuscripts reported the usefulness of molecular analysis for analyzing germplasm collections [13,14]. In the first, an SSR panel was adopted to analyze the official Algerian olive (Olea europea L.) collection highlighting a biodiversity hotspot in the Mediterranean Basin [13]. The olive germplasm was characterized using 16 nuclear (nuSSR) and six chloroplast (cpSSR) microsatellites, useful to underline the presence of an exclusive genetic core represented by 13 cultivars located in a mountainous area in the North-East of Algeria, named Little Kabylie. The genetic relationship of Algerian and Mediterranean olive germplasm was assessed, suggesting possible events of secondary domestication and/or crossing and hybridization across the Mediterranean area [13]. The second manuscript described the genetic diversity in sweet potato (Ipomea batatas L.) genetic resources by morphological and molecular markers [14]. The EU market of this orphan crop has recently increased by $100 \%$, and its cultivation in southern European countries is a new opportunity for the EU to exploit and introduce new genotypes. In this view, the origins of the principal Italian sweet potato clones, compared with a core collection of genotypes from Central and Southern America, were investigated by combining genetic analysis with morphological and chemical measurements [14]. Overall, these markers combination resulted as being effective to cluster the sweet potato clones in agreement with their geographical origin [14]. The last report included in this Special Issue focused on molecular markers supporting the in situ conservation of faba bean (Vicia faba L.) landraces in Tunisia [15]. The seed phenotypic features of the collected samples were analyzed, together with the genetic diversity and population structure, by using simple sequence repeat markers, highlighting 
the genetic stability of the population under study. These findings suggested that farmers applied international best practices for the in situ conservation of agricultural crops [15].

In conclusion, the Special Issue focused on the development and application of such technologies associated with adaptation and functional crop improvement, exploiting the available biodiversity in very different crops, from vegetables and legumes (eggplant, lettuce, sweet potato and faba bean), through important cereals (barley and corn) to very important Mediterranean trees (olive). This issue has allowed a scientific journey through the use of consolidated molecular markers, such as SSR, as well as novel classes of molecular markers obtainable by the new technologies (NGS). These were applied at the genetic analysis of germplasm collections, but also to the findings of new markers and QTL for assisted breeding programs.

Conflicts of Interest: The authors declare no conflict of interest.

\section{References}

1. Dzyubenko, N.I. Vavilov's Collection of Worldwide Crop Genetic Resources in the 21st Century. Biopreserv. Biobank. 2018, 16, 377-383. [CrossRef] [PubMed]

2. Nguyen, G.N.; Norton, S.L. Genebank Phenomics: A Strategic Approach to Enhance Value and Utilization of Crop Germplasm. Plants 2020, 9, 817. [CrossRef] [PubMed]

3. Cobb, J.N.; Biswas, P.S.; Platten, J.D. Back to the future: Revisiting MAS as a tool for modern plant breeding. Theor. Appl. Genet. 2019, 132, 647-667. [CrossRef] [PubMed]

4. Zamir, D. Improving plant breeding with exotic genetic libraries. Nat. Rev. Genet. 2001, 2, 983-989. [CrossRef] [PubMed]

5. Arrones, A.; Vilanova, S.; Plazas, M.; Mangino, G.; Pascual, L.; Díez, M.J.; Prohens, J.; Gramazio, P. The Dawn of the Age of Multi-Parent MAGIC Populations in Plant Breeding: Novel Powerful Next-Generation Resources for Genetic Analysis and Selection of Recombinant Elite Material. Biology 2020, 9, 229. [CrossRef] [PubMed]

6. Toppino, L.; Barchi, L.; Mercati, F.; Acciarri, N.; Perrone, D.; Martina, M.; Gattolin, S.; Sala, T.; Fadda, S.; Mauceri, A.; et al. A New Intra-Specific and High-Resolution Genetic Map of Eggplant Based on a RIL Population, and Location of QTLs Related to Plant Anthocyanin Pigmentation and Seed Vigour. Genes 2020, 11, 745. [CrossRef] [PubMed]

7. Thabet, S.G.; Moursi, Y.S.; Karam, M.A.; Börner, A.; Alqudah, A.M. Natural Variation Uncovers Candidate Genes for Barley Spikelet Number and Grain Yield under Drought Stress. Genes 2020, 11, 533. [CrossRef] [PubMed]

8. Wan, Y.; Zhang, M.; Hong, A.; Zhang, Y.; Liu, Y. Characteristics of Microsatellites Mined from Transcriptome Data and the Development of Novel Markers in Paeonia lactiflora. Genes 2020, 11, 214. [CrossRef] [PubMed]

9. Awata, L.A.O.; Beyene, Y.; Gowda, M.; Suresh, L.M.; Jumbo, M.B.; Tongoona, P.; Danquah, E.; Ifie, B.E.; Marchelo-Dragga, P.W.; Olsen, M.; et al. Genetic Analysis of QTL for Resistance to Maize Lethal Necrosis in Multiple Mapping Populations. Genes 2020, 11, 32. [CrossRef] [PubMed]

10. Li, P.; Wei, J.; Wang, H.; Fang, Y.; Yin, S.; Xu, Y.; Liu, J.; Yang, Z.; Xu, C. Natural Variation and Domestication Selection of ZmPGP1 Affects Plant Architecture and Yield-Related Traits in Maize. Genes 2019, 10, 664. [CrossRef] [PubMed]

11. Lebedev, V.G.; Subbotina, N.M.; Maluchenko, O.P.; Lebedeva, T.N.; Krutovsky, K.V.; Shestibratov, K.A. Transferability and Polymorphism of SSR Markers Located in Flavonoid Pathway Genes in Fragaria and Rubus Species. Genes 2020, 11, 11. [CrossRef] [PubMed]

12. Patella, A.; Palumbo, F.; Galla, G.; Barcaccia, G. The Molecular Determination of Hybridity and Homozygosity Estimates in Breeding Populations of Lettuce (Lactuca sativa L.). Genes 2019, 10, 916. [CrossRef] [PubMed]

13. Haddad, B.; Gristina, A.S.; Mercati, F.; Saadi, A.E.; Aiter, N.; Martorana, A.; Sharaf, A.; Carimi, F. Molecular Analysis of the Official Algerian Olive Collection Highlighted a Hotspot of Biodiversity in the Central Mediterranean Basin. Genes 2020, 11, 303. [CrossRef] [PubMed]

14. Palumbo, F.; Galvao, A.C.; Nicoletto, C.; Sambo, P.; Barcaccia, G. Diversity Analysis of Sweet Potato Genetic Resources Using Morphological and Qualitative Traits and Molecular Markers. Genes 2019, 10, 840. [CrossRef] [PubMed] 
15. Babay, E.; Khamassi, K.; Sabetta, W.; Miazzi, M.M.; Montemurro, C.; Pignone, D.; Danzi, D.; Finetti-Sialer, M.M.; Mangini, G. Serendipitous In Situ Conservation of Faba Bean Landraces in Tunisia: A Case Study. Genes 2020, 11, 236. [CrossRef] [PubMed]

Publisher's Note: MDPI stays neutral with regard to jurisdictional claims in published maps and institutional affiliations.

(C) 2020 by the authors. Licensee MDPI, Basel, Switzerland. This article is an open access article distributed under the terms and conditions of the Creative Commons Attribution (CC BY) license (http://creativecommons.org/licenses/by/4.0/). 